\title{
The War against Nicotine and Tobacco: New Tools?
}

The carcinogenic effect of tobacco was the most important discovery in the history of cancer epidemiology. In the decade 1990-2000 the estimated global tobacco-related death toll has reached the number of 3 million per year. In the period 2020-2030 the global tobacco-related deaths could exceed 10 millions annually. The WHO projects that one in ten people now alife will die of tobacco-related disease if we cannot change this situation for the better. Morbidity and death due to chronic lung disease, cardiovascular disease and cancer mainly of the lung are well-documented events in direct relation to the total amount of tobacco use over the lifetime. Women and adolescents are especially prone to develop tobacco-associated cancer early in their lifetime with half as many 'pack-years' compared to the average male smoker.

Unfortunately, most western governments earn a lot of money through the consumption of tobacco although the real medical and social costs of tobacco use exceeds the incomes of such revenues by far. The tobacco industry has a very powerful political lobby infiltrating all important organizations in order to keep their deadly smoking machinery going as efficiently and long as possible everywhere in the world.

Nicotine dependency provides the link through which smokers are repeatedly exposed to carcinogenic and genotoxic substances associated with tobacco consumption. Cigarettes contain 6-11 mg of nicotine, of which the smoker can absorb 1-3 $\mathrm{mg}$ - irrespective of nicotine-yield ratings provided by tobacco companies. This dose is sufficient to establish and sustain a nicotine dependency. A typical pack-per-day cigarette smoker absorbs 20-40 mg of nicotine each day, achieving plasma concentrations of $25-35 \mathrm{ng} / \mathrm{ml}$ by the afternoon.

The effect of nicotine on dopamine release (nucleus accumbens) and synthesis in the mesolimbic system may be important to the motivational and reinforcing properties of the drug. Dopamine release in the nucleus accumbens has been associated with self-administration of nicotine, opiates, and cocaine. Moreover, nicotine may stimulate 5-HT release in the median raphe nuclei, where high-affinity nicotine binding sites exist, as well as in serotonergic neurons in the hypothalamus and striatum. Such actions could have implications for understanding the relationship between smoking and depressed mood, given the favorable clinical response of patients with major depression treated with serotonin reuptake inhibitors.

The majority of smokers want to stop smoking completely; however, the estimated rate of successful quitting is only $2.5 \%$ of all smokers per year. The rate of 'self-quitters' for continuous abstinence one year after their cessation attempt is only $4.3 \%$. The nicotine withdrawal syndrome is well-known and includes symptoms of increased anxiety, irritability, and appetite as well as decreased cognitive capabilities and heart rate. Withdrawal symptoms peak within a few days and then begin to recede over the next several weeks. However, most individuals who try to quit smoking relapse before the syndrome subsides. Nicotine replacement does not appear to shorten the course of the syndrome, but it can reduce severity of the symptoms to the more tolerable levels typically observed after about 4-5 weeks of untreated abstinence. Some withdrawal symptoms, particularly cognitive impairment, cravings, and irritability, may persist for months.

Therefore, there is an urgent need for innovative and effective tools to help smokers quit. Two articles in this issue of ONKOLOGIE deal in very different but complementary ways with the problem of smoking cessation. The review by Cornuz [1] addresses counseling and accompanying the smoker through the difficult phase of cessation and staying tobaccofree as a well established but often neglected strategy. A new method to overcome the nicotine addiction is vaccinating smokers against nicotine in order to prevent the nicotine molecule to enter the CNS in sufficient amounts. This new promising approach has just entered phase 1 in some centers in Europe and the US, and results of the preclinical work are summarized in the original article by E.H. Cerny et al. [2].

T. Cerny, St. Gallen

\section{References}

1 Cornuz J: Smoking Cessation in Primary Care Medicine. Onkologie 2002;25: 413-418.

2 Cerny EH, Lévy R, Mauel J, Mpande M, Mutter M, Henzelin-Nkubana C, Patiny L, Tuchscherer G, Cerny T: Preclinical Development of a Vaccine 'Against Smoking'. Onkologie 2002;25:406-411.

\begin{tabular}{ll}
\hline KARGER & ๑ 2002 S. Karger GmbH, Freiburg \\
Fax +497614520714 & Accessible online at: \\
$\begin{array}{l}\text { E-mail Information@Karger.de } \\
\text { www.karger.com }\end{array}$ & www.karger.com/journals/onk
\end{tabular}

